PÉTER TÖRÖK* ${ }^{*}$ ISTVÁN NAGY \& MÁTÉ JOÓB

\title{
DIE KARITATIVE TÄTIGKEIT DER TRADITIONELLEN CHRISTLICHEN KIRCHEN IN UNGARN WÄHREND DES KOMMUNISMUS UND IHRE WIRKUNG AUF DIE KIRCHLICHE WOHLTÄTIGKEIT IM POSTKOMMUNISMUS
}

\author{
Teil 2
}

(Erhalten: 23. Februar 2009; angenommen: 21. April 2009)

\begin{abstract}
Die aus zwei Teilen bestehende Studie analysiert die karitative Tätigkeit der traditionellen christlichen Kirchen in Ungarn während des Kommunismus. Dabei werden nicht nur die Fakten aufgedeckt und beschrieben, sondern es erfolgt auch ein Ausblick auf die Wirkung dieser Tätigkeit auf die karitative Tätigkeit der Kirchen im Postkommunismus. Dieser erfordert unbedingt auch eine kurze Erörterung der Frage nach Art und Umfang der karitativen Tätigkeit der katholischen, reformierten und evangelischen Kirche vor der kommunistischen Machtergreifung. Ein Großteil der kirchlichen sozialen Institutionen gelangte nach dem Zweiten Weltkrieg unter staatliche Verwaltung, die neuen Mitarbeiter betrachteten die Erfüllung ihrer Aufgaben als reinen Broterwerb, ihnen fehlte das Engagement für ihren Dienst. Es war klar erkennbar, wie die staatssozialistische Politik die Caritas und die Diakonie für ihre Kirchen und Religion zerstörenden Bemühungen zu nutzen versuchte. Dies war das Ziel der Maßnahmen, die dazu führten, dass fast nur solche Einrichtungen in konfessioneller Hand bleiben konnten, in denen es keinerlei oder nur sehr geringe Möglichkeiten zur Mission gab. Auch die kirchlichen Führungspersonen, die das Überleben durch Erfüllung der Erwartungen von Seiten der Behörden zu sichern versuchten, wurden teilweise zu Partnern der Staatsmacht. Es bedeutete einen Fortschritt, als die Stellen in den staatlichen sozialen Einrichtungen, die schlecht bezahlt und mit schwieriger Arbeit verbunden waren und viel Engagement verlangten, auf Grundlage von Empfehlungen und Nominierungen der Kirche mit ausgebildeten und fähigen Arbeitskräften besetzt wurden. Während der Zeit der Diktatur war die karitative Tätigkeit in den Gemeinden und Pfarreien nämlich stark zurückgedrängt worden. Bei allen drei Kirchen ist die Absicht zu erkennen, sich in ihrer nach der Zeit der Diktatur neu erstehenden karitativen Tätigkeit trotz des notwendigerweise eintretenden Institutionalisierungsprozesses und strikter Professionalität ihre Gesinnung und ihr Charisma zu bewahren. Die Analyse weist auch auf einige Fälle hin, die das Augenmerk auf Stolpersteine im Kontakt mit dem postkommunistischen Staat lenken. Im

\footnotetext{
* Kontaktautor: Péter Török, Institut für Mentalhygiene, Semmelweis-Universität, Nagyvárad tér 4., 19. em., H-1089 Budapest, Ungarn; torokp@mental.usn.hu.
} 
ersten Teil der Studie wurden die Arbeitsmöglichkeiten der den protestantischen Kirchen angehörenden Hilfsdienste vorgestellt. Der zweite Teil gibt nach ähnlichen Gesichtspunkten einen Überblick über die Existenzbedingungen der katholischen Caritas in den Jahren der kommunistischen Diktatur, bezieht aber auch die Zeit vor dem Zweiten Weltkrieg und die veränderten Möglichkeiten nach der Wende von 1989 mit ein.

Schlüsselbegriffe: Diakonie, Ungarn, Kommunismus, Diktatur, Geschichte, Rückblick, helfender Beruf, Institutionalisierung, lokale Initiative, Beziehung zwischen Kirche und Staat

Charitable Activities of Historical Christian Churches in Hungary during Communism, and their Effects on Post-Communist Charitable Church Activities; Part 2: In addition to assessing charitable activities of historical Christian churches in Hungary during Communism from a fact-finding, descriptive angle, this two-part study also provides a view of what effects these have had on post-Communist charitable church activities. Understandably, this necessitates a brief overview of the types and volume of charitable activities carried out by the Catholic, Reformed and Lutheran churches prior to the Communist power grab. In the years following the Second World War, the majority of church-run social institutions came under State control. The new employees often looked upon the tasks they were to carry out only as a way of making a living, and they lacked a commitment to the service they were to perform. The way in which State Socialist politics strove to use charity and the diaconate in their efforts was aimed at exhausting church and faith, and can be clearly observed. The measures, according to which practically only those institutions where missionary work was impossible (or possible only to a minor degree) could remain in church hands, also served this end. Church leaders who tried to ensure survival by adhering to the official line, also partly became partners to the state. It was considered a step forward when badly paid positions that required hard work and commitment at State-run social institutions were filled by qualified, able labour based on church recommendations and nominations. During the period of dictatorship, charitable activities by congregations and parishes also experienced a strong setback. Following the collapse of Communism, all three churches displayed the intention of reviving their charitable activities by maintaining spirituality and charisma despite a necessary institutionalisation process and strict professionalism. The analysis also pinpoints some cases that highlight the pitfalls of relations with the post-Communist state. The first half of the study presented the operation of helping services linked to Protestant churches, with the Reformed and Evangelical churches discussed separately. The second part provides an overview of the conditions of Catholic charity during the years of dictatorship, using similar considerations, and also takes a look at the times before the Second World War and the changed circumstances following the fall of Communism in 1989.

Keywords: diaconate, Hungary, communism, state socialism, dictatorship, history, retrospect, helping profession, institutionalisation, local initiative, church-state relations

\section{Die karitative Tätigkeit der Katholischen Kirche in Ungarn}

Bei den Katholiken wurde die Beziehung zwischen der Kirche und dem kommunistischen Staat zum großen Teil durch die Existenz des Vatikans als zentrales und höchstes Organ des Katholizismus geprägt, der nicht nur in theologischer, sondern auch in politischer Hinsicht das übergeordnete Organ der katholischen Kirchen in den einzel- 
nen Ländern ist. ${ }^{1}$ Eine der Folgen ist, dass sich die Katholische Kirche in Ungarn zwar der durch die kommunistische Diktatur entstandenen Situation ${ }^{2}$ anpassen musste, sich aber dennoch keine vom Lehramt der römisch-katholischen Kirche unabhängige, spezifisch ungarische Theologie karitativer Tätigkeit herausbildete.

\subsection{Die karitative Tätigkeit der Katholischen Kirche in Ungarn vor dem Kommunismus}

Während des Eucharistischen Kongresses in Amsterdam im Jahre 1924 wurde auch eine Caritas-Konferenz in Luzern unter Teilnahme von 22 Ländern organisiert, bei der der internationale Caritas-Verband (Caritas Internationalis) gegründet wurde. Auch Ungarn gehörte zu den Gründern. Ohne Zweifel war diese Ungarische Caritas mit ihren Zentralen und Unterorganisationen in den Diözesen bis zu ihrem Verbot 1945 das Flaggschiff der karitativen Tätigkeit in Ungarn. Daneben beteiligten sich aber auch die Orden an dieser Arbeit, insbesondere die Frauenorden. Über neuntausend Ordensschwesternbetriebe in 44 Orden 173 Anstalten für Sozialfürsorge: in 46 Orten sog. Altersheime, in 18 Orten Kinder- und Mädchenheime, in 21 Orten unterschiedliche Gemeindehäuser und darüber hinaus noch 70 Kindergärten (GERGELY 1985).

\subsection{Die karitative Tätigkeit der Katholischen Kirche in Ungarn während des Kommunismus}

\subsubsection{Die Gliederung der kommunistischen Diktatur in Zeitabschnitte}

Die Entwicklung der Beziehungen zwischen dem sozialistischen Staat und der Kirche von 1945 bis 1956 kann in drei voneinander deutlich unterscheidbare Zeitabschnitte gegliedert werden. In der Periode zwischen 1945 und 1956 wollte die staatliche Kirchenpolitik die Kirchen und die Religion abschaffen. Die katholische Kirche leistete in diesem Zeitabschnitt unter der Leitung von Kardinal József Mindszenty Widerstand. Zwischen 1957 und 1964 ließ die staatliche Religionsverfolgung zwar etwas nach, hörte aber nicht auf. Die Kádár-Regierung kündigte eine Volksfrontpolitik ${ }^{3}$ an,

\footnotetext{
${ }^{1}$ Zur Beziehung zwischen Kirche und Staat siehe im Allgemeinen TÖRÖK (2003); zur sog. OstPolitik der Katholischen Kirche siehe z.B. CASAROLI (2001) oder Ring-EIFEL (2004, insbesondere die Seiten 138-49).

${ }^{2}$ Ihr Ergebnis war die sog. „Politik der kleinen Schritte“, die von staatlicher Seite von Imre MiKLÓs (1987) geleitet wurde, seitens der Kirche aber mit dem Namen Kardinal László Lékai verbunden war. Ihre Widersprüche werden z.B. in ANDRAS \& MOREL (1983) offen gelegt.

${ }^{3}$ Die Patriotische Volksfront (HNF) war eine eigentümliche gesellschaftliche Organisation zwischen 1954 und 1990. Durch ihre Gründung hatte Ministerpräsident Imre Nagy, der in der Revolution 1956 eine führende Rolle innehatte, den Staatsbürgern, die keine Mitglieder in der kommunistischen Partei (MDP) waren, eine politische Rolle ermöglichen wollen. Es gab keine individuelle Mitgliedschaft, die HNF war eine sog. Massenbewegung.
} 
die Katholische Kirche wurde in der Gesellschaft allmählich isoliert. Kennzeichnend für die Periode zwischen 1965 und 1989 war die Suche nach Kompromissen in der Beziehung zwischen Staat und Kirche, hauptsächlich wegen der Zunahme der gesellschaftlichen Probleme. ${ }^{4}$ Der Piarist Ottó Virányi hat die Zeitperiode nach 1980 in einem Interview wie folgt charakterisiert: „Nach $1980 \ldots$. begannen schon mildere Winde zu wehen. Ich will nicht den Begriff 'lustige Baracke' verwenden, aber zu dieser Zeit hat der Staat festgestellt und es ist ihm bewusst geworden, dass er [die soziale Tätigkeit auf Landesebene] allein nicht schaffen kann ... man hat für alles die prinzipielle Zustimmung gegeben, also keine Genehmigung, sondern die prinzipielle $\mathrm{Zu}$ stimmung. “5 Darüber hinaus hat die vor der Wende letzte, so genannte „reformkommunistische“ Németh-Regierung Maßnahmen getroffen, auf Grund deren mehr Hilfe für Familien und Jugendliche durch kirchlichen Sozialeinrichtungen geleistet werden konnte.

\subsubsection{Die karitative Tätigkeit der Katholischen Kirche während der Diktatur}

Die Diktatur hat in ihrem Kampf gegen die Kirche die institutionellen Fundamente der karitativen Tätigkeit der Kirche vernichtet. Die Caritaszentren der Diözesen wurden aufgelöst, durch die Verordnung 34/1950 wurde allen - außer vier ${ }^{6}$ - Orden, die sich mehrheitlich mit Krankenpflege bzw. Unterricht beschäftigt hatten, die Genehmigung entzogen. Der Staat hat das Eigentum und die Häuser der Ordensleute beschlagnahmt, die Ordensleute durften nicht im kirchlichen Dienst stehen, sie mussten sich eine weltliche Beschäftigung suchen. Die Situation der alten und kranken Ordensmitglieder war aussichtslos.

Im Oktober 1950 wurde die Gründung der karitativen Organisation „Liebesdienst der Römisch-Katholischen Kirche“ (im Weiteren: Caritasdienst der Kirche) - scheinbar zur Lösung der sozialen Probleme der Gesellschaft, in Wirklichkeit aber zur Verunmöglichung der Caritasarbeit - vom Staat praktisch verordnet. Bis zum Jahre 1989 konnte ausschließlich der Caritasdienst der Kirche - in einem sehr engen Rahmen eine institutionell organisierte karitative Tätigkeit in Ungarn leisten.

Die Tätigkeit und die Auslandsbeziehungen des Caritasdienstes der Kirche wurden insbesondere seit der Entstehung des Staatlichen Kirchenamtes (ÁEH) am 19. Mai 1951 ständig von der sozialistischen Staatsmacht kontrolliert. Es bestanden während des Sozialismus in Ungarn 17 Sozialheime für Kirchenleute, davon wurden 6

\footnotetext{
${ }^{4}$ Manche betrachten bzgl. der Zuordnung zu Epochen nicht 1965, sondern 1960 als Wendepunkt. Die Zeitabschnitte in unserer Studie basieren - mit geringfügigen Änderungen - auf der Studie von Miklós TOMKA (1996). Zu diesem Thema siehe auch: GÖRGÖY (2001).

${ }^{5}$ Eigene Übersetzung. Originaltext: „1980 -tól kezdve . . . már kezdődtek a csendesebb szelek. Nem akarom használni a 'vidám barakk' elnevezést, akkor az állam már észrevette és megtudta, hogy nem tudja egyedül [az országos szociális tevékenységet] csinálni ... akkor bármihez hozzáadták az elvi hozzájárulást, tehát nem engedélyt, hanem az elvi hozzájárulást.“

${ }^{6}$ Die Benediktiner, Franziskaner, Piaristen und die Armen Schulschwestern.
} 
vom Staat ${ }^{7}, 11$ von der Kirche ${ }^{8}$ (also im Rahmen des Caritasdienstes der Kirche / der Diakonie) getragen. In den Heimen wurden von insgesamt 460 bis 500 Mitarbeitern etwa 980 bis 1000 Personen betreut, im Heim in Székesfehérvár waren Priester, in Tiszaalpár und in Soroksár Männer und Frauen, in allen anderen aber alte Frauen untergebracht. Zu den Umständen in den Sozialeinrichtungen hat der Leiter des Caritasdienstes der Kirche Ottó Virányi hervorgehoben, dass „Jászberény . . ein Franziskanerkloster war, Pannonhalma aber ein Benediktinerkloster. Man kann sich vorstellen, wie in einer kleinen Mönchzelle vier Priester gewohnt haben . . . In Hejce gibt es bis zum heutigen Tag keine Zentralheizung, man trägt dann 15 Eimer Kohle hoch. Stellen Sie sich bitte vor, dass das Personal um drei Uhr weggeht, wer entfernt dann die Asche, und wer macht Feuer ... Hejce ist sonst ein wunderbares bischöfliches Erholungsschloss mit zwei Etagen, mit sehr breiten Dielen und 5 Meter hohen Wänden. Da wurde viel gefroren, man hätte ja auch drei Öfen auf einmal beheizen können.“`

Die sozialistische Staatsmacht konnte den sich Anfang der 1970er Jahre häufenden Problemen der Gesellschaft (Alten-, Kranken- und Behindertenfrage, Schwerbeschädigte, Alkohol- und Drogensüchtige, der steigenden Zahl der Scheidungen, der rückgängigen Geburtenzahl, der Verbreitung des Schwangerschaftsabbruchs, dem Ansteigen der Selbstmordrate usw.) nicht gerecht werden. In den Beratungen der Patriotischen Volksfront verlautete bereits, dass die Kirchen auf sozialem Gebiet Dienste für die Gesellschaft leisten könn(t)en, insbesondere bei der Schaffung von mehr Ordnung im Familienleben, bei der Pflege der alten und kranken Leute. Es stand aber natürlich auch da noch nicht zur Debatte, die Orden, die sich mit Krankenpflege und sozialen Angelegenheiten beschäftigt hatten, wieder aufzubauen.

Das sich infolge der immer schwerwiegenderen gesellschaftlichen Probleme verbreitende Volksfrontprogramm machte es der Katholischen Kirche im Jahre 1981 möglich, ihr Altersheim Papst Johannes XXIII. in Budapest-Farkasrét zu errichten. Die Genehmigung für die Errichtung wurde der Kirche vom Staat anlässlich des 50. Jahrestages der Priesterweihe von Kardinal László Lékai „als Gabe“ „geschenkt“, die damit verbundenen Kosten wurden aber von den Bewohnern übernommen, unterstützt von landesweiten Sammlungen sowie in- und ausländischen Spendern (MÉSZÁROS 1995).

\footnotetext{
${ }^{7}$ Bakonybél, Csákvár, Dabas-Gyón, Hejce, Jászberény und Pannonhalma.

${ }^{8}$ Das Prohászka-Heim des Bistums in Pécs, die Heime für Sozialfürsorge in Hévíz, Piliscsaba, Püspökszentlászló, Soroksár, Székesfehérvár, Tiszaalpár, Vác und Veröce.

${ }^{9}$ Eigene Übersetzung. Originaltext: „Jászberény . . . ferences kolostor volt, Pannonhalma pedig bencés. El lehet képzelni, hogy egy kis [szerzetesi] cellában négy pap lakott ... Hejcén mind a mai napig nincs központi fütés, hanem visznek föl 15 vödör szenet. Tessék elképzelni, hogy a dolgozók háromkor elmennek, és akkor ki szedi ki a hamut, ki rak tüzet . . . Hejce egyébként egy két emeletes gyönyörü püspöki nyaralókastély, igen széles hajópadlókkal, és öt méter magas falakkal. Ott vacogni lehet, mert egyszerre három kályhát be lehetne füteni." Das Interview wurde im Rahmen des Projekts Aufbruch 2001 aufgenommen. Wenn anders nicht angegeben, stammen die Daten im Zusammenhang mit der karitativen Tätigkeit der Ungarischen Katholischen Kirche aus der Studie, die im Auftrag des Aufbruch angefertigt wurde (TÖRÖK \& GÖRGÖY (2001) ‘Karitász Magyarországon 1948-2000’, Manuskript).
} 
Zum Tätigkeitsbereich der Caritas der römisch-katholischen Kirche gehören seit 1980 die Pastoral für blinde Kinder, das Sankt-Anna-Heim ${ }^{10}$ an der Pfarrei am Batthyány-Platz, die Außenstelle Ulászló-Straße in Budapest ${ }^{11}$, ebenfalls in der Hauptstadt das Pensionistenhaus Radványi-Straße, die Bildungsstätte für Mitarbeiter des Caritasdienstes „Hl. Margit aus der Arpadendynastie“"12, das geistliche Zentrum in Iszkaszentgyörgy, der Samariterverein für „Trinkerrettung“, der soziale Hilfsdienst Betania, das Tagesheim „Hl. Margit aus der Arpadendynastie“, das Medizinische Kinderheim Hl. Elisabeth für geistig behinderte Kinder ${ }^{13}$ und die Erholungsstätte in Csatka.

Nicht zuletzt sind bei der Erörterung der nicht zentral organisierten CaritasTätigkeit auch andere, gelegentlich sehr eigenartig konstruierte Sozialeinrichtungen zu erwähnen. Die erste Institution, die in der Zusammenarbeit von Staat und Kirche entstand, war das bereits erwähnte Altersheim Johannes XXIII. Danach folgte unmittelbar vor der Wende das Familienhilfezentrum HÍD (Brücke), das von dem Ehepaar Roger Csáky-Pallavicini und Teodóra Tomcsányi gegründet und von der Kirche und dem Bezirksrat getragen wurde. Dieses Zentrum konnte mit Hilfe von damals die Seiten wechselnden führenden sozialistischen Politikern - der Ministerin Judit Csehák und des Staatssekretärs István Bánfalvi - errichtet werden und wurde zu $83 \%$ aus dem Staatsbudget; es zu 17\% aus Kirchengeldern finanziert. Der Leiter des Zentrums konnte von der kirchlichen Caritas bestimmt werden und durfte sich dann seine Mitarbeiter selber aussuchen. ${ }^{14}$

Als Initiative von unten galt die Betánia-Bewegung von Frau Edina Bogláryné Majláth, die sich die Unterstützung der Armen zum Ziel gesetzt hatte und gemeinsam mit dem Priester Endre Halász eine Mission für die Rettung von Trinksüchtigen unterhielt. Nennenswert sind noch der karitative Verein „Bewegung für das Leben“, der von Teodóra Tomcsányi ins Leben gerufene katholische Caritas-Dienst für seelische Erste Hilfe sowie eine Gruppe von Jugendlichen, die Hilfspakete für bedürftige Ungarn in den Nachfolgestaaten geliefert haben.

Seit 1989 gibt es in Ungarn das bürgerliche Freiheitsrecht, zivile Vereine und Organisationen zu gründen. Auf dieser Grundlage wurde am 4. Februar 1989 der Malteser Hilfsdienst in Ungarn (MMSZ) im Geiste der neunhundert Jahre alten Idee des Souveränen Malteser Ritterordens „Schutz des Glaubens, Dienst an den Armen“ unter der Leitung von Pfarrer Imre Kozma in Zugliget gegründet. Eine entscheidende Rolle bei der Errichtung des Malteser Hilfsdienstes in Ungarn hatten die aus Ungarn stammende Csilla Freifrau von Boeselager und Mária Terézia Gräfin Zichy, deren Tätigkeit, Entschlossenheit, Beziehungen und nicht zuletzt Vermögen dringend benötigt

\footnotetext{
${ }^{10}$ Eröffnet im September 1982.

${ }^{11}$ Seit Dezember 1983.

${ }^{12}$ Die Ausbildungsstätte war zwischen 1984 und 1987 in Pécs, seit dem Herbst 1987 ist sie in Iszkaszentgyörgy.

${ }_{13}^{13}$ Besteht seit dem 25. September 1986.

${ }^{14}$ Das HÍD arbeitete bis Ende 1997 in dieser Konstruktion. Anschließend verlegte der Ungarische Caritasverband den Schwerpunkt auf die Caritas-Organisationen in den Diözesen und stellte die Förderung solcher zentralen Anstalten ein. Seitdem gehört das HÍD zu den Sozialeinrichtungen eines Budapester Stadtbezirkes und wird von der Bezirksverwaltung getragen.
} 
wurden, da eine institutionelle karitative Tätigkeit nach 1945 nur die 1950 errichtete und vom Staat kontrollierte Caritas (der Liebesdienst) der Römisch-Katholischen Kirche leisten konnte. Dies bedeutete - wie bereits erwähnt -, dass die katholische Kirche in Ungarn keine institutionellen, von staatlicher Kontrolle unabhängigen Mittel für die Lösung verschiedener gesellschaftlicher Probleme zur Verfügung hatte (FARKAS 2000).

Der Malteser Hilfsdienst in Ungarn ist ein außerordentlich gemeinnütziger Verein. Der ungarische Malteser Hilfsdienst wurde im Jahre 1989 vom Staat weder finanziell noch durch die Überlassung von Immobilien unterstützt. Seine Tätigkeit wurde vollständig aus Spenden finanziert - zum Teil aus der ungarischen, überwiegend aber aus der ausländischen Wirtschaftssphäre (FARKAS 2000). Zwischen August und November 1989 - also in der Periode bis zum Sturz der Berliner Mauer - sorgte der MMSZ für die Verpflegung von 50.000 ostdeutschen Flüchtlingen, finanziell unterstützt durch den deutschen Malteser Hilfsdienst. Auf deutschen Druck, sozusagen als „Gegenleistung“ für seine Rolle in der Flüchtlingsfrage hat die letzte Regierung des alten Systems dem MMSZ 1990 eine sanierungsbedürftige Kaserne der Arbeiterwache (Pendant zu den Betriebskampftruppen in der DDR) im 3. Budapester Bezirk zur Verfügung gestellt. Bis heute dient dieses Gebäude als Zentrale des MMSZ in Budapest. ${ }^{15} 1990$ erhielt der MMSZ zum ersten Mal finanzielle Unterstützung vom ungarischen Staat für die Errichtung eines Obdachlosenheimes und von ärztlichen Sprechzimmern. Einen größeren Zuschuss erhielt die Organisation erstmals im Jahre 1991 (FARKAS 2000). Die Budapester Zentrale des MMSZ hat seit 1990 ein sehr komplexes Versorgungssystem für Obdachlose entwickelt, das über fast alle Komponenten der Fürsorge für obdachlose Menschen verfügt. Darüber hinaus besteht ihre Tätigkeit in der Beteiligung an der Bewältigung von Katastrophen- und Krisensituationen, in der Einrichtung von Notküchen und in der Altenversorgung; darüber hinaus hat sie auch ein Spielplatzprogramm. Wie bereits erwähnt, stellt der Malteser Hilfsdienst in Ungarn keine Institution der Katholischen Kirche dar. Sie war vor 1990 als informelle karitative Organisation in Ungarn tätig. Tatsächlich ist der MMSZ aus der vom Pfarrer Imre Kozma geleiteten Gruppe an der Pfarrei Zugliget entstanden, die Teil der „Untergrund-Caritas“" war.

Die „Untergrund-Caritas“ existierte auch nach 1948 durchgehend weiter. Einerseits waren die früher schon bestehenden Kleingemeinden (die Maria-Kongregation, die von einem Jesuiten organisierte Gebetsgemeinschaft „Szívgárda“ [„Herzgarde“], die Kleingruppen der Pfadfinderbewegung, die Gemeinschaften von „Regnum Marianum“") mit mehr oder weniger Schwung, zum Teil mit zeitweiliger Unterbrechung und schwankender Anzahl tätig, andererseits entstanden neue Kleingemeinschaften, die so genannten Basisgemeinschaften (z.B. die Bokor- [Busch]-Gemeinschaft). ${ }^{16}$ Obwohl

\footnotetext{
${ }^{15}$ Die Vertretungs- und Leitungsorgane des MMSZ auf mittlerer Ebene sind die regionalen Organisationen in Pest, Pécs, Győr, Miskolc, Szeged, Szombathely und Veszprém (vergl. TÖRÖK \& LEGEZA 1999, 46-47).

${ }^{16}$ Eine Gemeinschaft, die 1945 von dem Piaristenbruder und Lehrer György Bulányi ins Leben gerufen wurde, und deren primäres Ziel es war, christliches Denken, Glauben und Leben über die Zeit der
} 
die kommunistischen Machthaber im Anschluss an den Parteibeschluss (MÉSZÁROS 1995) der USAP vom 22. Juli 1958 eine Reihe von Schauprozessen ${ }^{17}$ gegen die Leiter der Kleingemeinschaften eingeleitet haben, haben die Kleingemeinschaften weitergelebt, seit Mitte der 1970er Jahre sind sogar neue entstanden, ihr Tätigkeitsbereich hat sich ausgedehnt, ihre Jugendarbeit wurde inhaltlich reicher. Ein wichtiger Teil des Lebens dieser Kleingemeinschaften war (und ist auch heute noch) die Caritas (der Liebesdienst). Die Mitglieder haben gelernt, wie sie zwar nicht unter kirchlicher Leitung, aber in der Vertretung christlicher Werte soziale, gesellschaftliche Aufgaben erfüllen können. Die Worte des katholischen Priesters Ferenc Tomka charakterisieren die Tätigkeit einer dieser Gemeinschaften (das „Regnum Marianum“) sehr präzise:

Man könnte viel darüber schreiben, wie sie in den letzten Jahrzehnten regelmäßig Altersheime und Hospizstationen besucht, alte Leute in ihrer Wohnung betreut, Kranke gepflegt, geistig oder körperlich behinderte Kinder und Erwachsene auf Ferienfreizeiten begleitet haben usw. (auch dann, wenn sie dabei ihr christliches oder kleingemeinschaftliches Engagement verheimlichen mussten). Und diese Tätigkeit war nicht nur eine positive Tatsache, sondern auch ein Zeichen in einem menschlichen Milieu, in dem eine derartige Haltung oft Mangelware war.

(MÉSZÁROS 1995, 76)

\subsection{Karitative Tätigkeit in der postkommunistischen Zeit}

Nach dem Beschluss der Ungarischen Katholischen Bischofskonferenz im Juni 1990 wurde die zwischen 1924 und 1945 tätige, aber 1945 durch die kommunistische Macht aufgelöste Ungarische Caritas (Magyar Karitász) neu gegründet. Mit der Leitung und Durchführung organisatorischer Aufgaben wurde von der Bischofskonferenz der katholische Pfarrer Miklós Frank ${ }^{18}$ beauftragt, den seine Vorgesetzten noch vor der kommunistischen Machtübernahme zur Fortbildung ins Ausland geschickt hatten. Er war nach der kommunistischen Machtübernahme im Ausland geblieben und hatte sich der Arbeit der seit 1924 tätigen Internationalen Caritas angeschlossen. Die Ungarische Caritas ist die offizielle Hilfsorganisation ${ }^{19}$ der Katholischen Kirche in Ungarn, die eine Zeit lang parallel zu der unter der Diktatur entstandenen Kirchlichen Caritas tätig war, dann aber unter die Aufsicht der Ungarischen Caritas kam. Zur Förderung ihrer sozialen und karitativen Arbeit (Kranken- und Armenpflege sowie andere Wohlfahrtstätigkeiten) hat die Ungarische Caritas am 18. März 1991 die Stiftung Ungarische

kommunistischen Diktatur hinüberzuretten. Vermutlich aufgrund staatlichen Drucks hat die Ungarische Katholische Bischofskonferenz György Bulányi die Berechtigung zum öffentlichen Messelesen entzogen und diese Restriktion erst auf Druck des Vatikans 1997 aufgehoben.

${ }_{17}^{17}$ Der erste Schauprozess fand im Jahre 1961, der letzte 1972 statt.

${ }^{18}$ Ein bedeutender Teil der Angaben zur Ungarischen Caritas stammt aus dem Interview von Péter Török mit Miklós Frank (am 13. September 2000 in der Bartók Béla út 30., 1111 Budapest), die übrigen sind Miklós Franks Studie Caritas in Ungarn - Auferstehung und Aufbruch entnommen.

${ }^{19} \mathrm{Ihr}$ Statut wurde auf der Sitzung der Ungarischen Katholischen Bischofskonferenz am 11. und 12. März 1991 gebilligt und am 14. Juni 1991 (Gerichtsverfügung des Hauptstadtgerichts Budapest, 9. Pk. $61123 / 1$ ) gerichtlich eingetragen. 
$\operatorname{Caritas}^{20}$ ins Leben gerufen. Die Umstufung der Stiftung zur außerordentlich gemeinnützigen Organisation erfolgte am 26. April 1999. ${ }^{21}$

Die Internationale Caritas (Caritas Internationalis) hat auf ihrer 14. Generalversammlung vom 23-29. Mai 1991 in Rom die Ungarische Caritas als Mitglied aufgenommen. Dadurch wurde die Ungarische Caritas automatisch auch Mitglied in der Europäischen Caritas (Caritas Europa). In jeder Diözese wurden Caritasorganisationen auf Diözesanebene gegründet und bis zum Jahre 1995 entstand das Landesnetz der Caritas in Ungarn. Neben der Freiwilligenarbeit hat die Hilfsorganisation ab 1994 landesweit eigene soziale und Gesundheitseinrichtungen errichtet ${ }^{22}$ und sich zunehmend an Hilfsaktionen und -programmen der internationalen Caritas beteiligt.

Der Ungarische Caritasverband wurde nach dem Konzept von Miklós Frank aufgebaut. Dies bedeutet, dass einerseits eine Landesorganisation aufgebaut wurde, deren Struktur sich an die der Diözesen und Pfarreien anlehnt, andererseits auch die „Privatinitiativen" der katholischen Gläubigen zusammengefasst, koordiniert und je nach Möglichkeit gefördert werden. So sagte Miklós Frank in einem Interview über die Umstände der Organisation der Ungarischen Caritas:

Ihrem ursprünglichen Ziel gemäß soll die Caritas als Dachorganisation (umbrella organization) fungieren, die alle katholischen karitativen Tätigkeiten zusammenführt. Diese Zielsetzung wird aber nur formal erfüllt, indem die verschiedenen Organisationen auf der Jahresversammlung des Landesrates der Caritas erscheinen. Mit anderen Worten, die Bewegung und die Institution sind da, was nicht gelungen ist, ist die Institutionalisierung der katholischen Initiativen. Zum Vergleich ist zu erwähnen, dass alle katholischen karitativen Organisationen in Deutschland - Kindergärten, Obdachlosenheime usw. - automatisch auch Mitglieder der Caritas sind. . . . Der Ungarische Caritasverband ist horizontal und vertikal aufgebaut. Horizontal, weil sie sich auf das ganze Land erstreckt, vertikal insofern, als die ganze Bewegung auf den Pfarreien aufgebaut ist, die sich dann in der Caritas der Diözesen zusammenfinden, die dann wiederum der Landescaritas unterstellt sind. . . Leider ist es wegen der Überbelastung bzw. wegen des übermäßigen Engagements der Pfarrer schwierig, in jeder Pfarrei eine örtliche Caritasgruppe zu bilden. Obwohl alle meinen, sie könnten karitative Tätigkeit leisten, ist das in Wirklichkeit gar nicht so einfach. Deshalb müssen Ausbildungskurse für Caritasmitarbeiter organisiert werden. ${ }^{23}$

${ }^{20}$ Eingetragen am 16. Mai 1991 (Hauptstadtgericht Budapest, 9. Pk. 66040/1).

${ }^{21}$ Hauptstadtgericht Budapest, 11. Pk. 66040/91/8.

${ }^{22}$ Einrichtungen, deren Trägerin der Ungarische Caritasverband ist: der Suchtkranken-Hilfsdienst „Rév“ (Fährenhafen) des UCV, das Altersheim und Hospizhaus „Johannes XXIII.“, Batthyány-LászlóKinderheim, Kindergarten und Grundschule für Blinde, Sozialdienst der Ungarischen Eisenbahn und das Familienhilfezentrum HÍD (Brücke).

${ }^{23}$ Eigene Übersetzung. Originaltext: „Az eredeti cél az volt, hogy a Karitász egy olyan ernyőszervezet (umbrella organization) legyen, amely összefog minden katolikus karitatív tevékenységet. Ez a cél csak formailag valósult meg, amennyiben az Országos Karitász Tanács évi gyülésén a különféle szervezetek megjelennek. Más szóval a mozgalom és az intézmény megvan, ami nem sikerült, az a katolikus kezdeményezések intézményesülése. Összehasonlításként érdemes megjegyezni, hogy Németországban minden katolikus karitatív szervezet - óvodák, menhelyek stb. - automatikusan részei a Karitásznak. . . . A magyar Karitász horizontálisan és vertikálisan épül fel. A horizontális rész az egész országra való kiterjedtséget jelöli, míg a vertikális azt, hogy a mozgalom a plébániákra épül, azok az egyházmegyei Karitászba csopor- 
Die Aufgabe der Diözesancaritasstellen ist es, die Caritasgruppen zu leiten, fachlich und seelsorgerlich zu betreuen, die Mitglieder auszubilden und die Caritas-Sammlungen auf Diözesanebene durchzuführen. Der Leiter dieser Verbände ist der jeweilige Bischof der Diözese. Ihre Arbeit wird vom Prinzip der Subsidiarität geleitet. Die Fachgruppen sind vollberechtigte Mitglieder der Ungarischen Caritas, genießen aber in ihrer Arbeit vollständige Unabhängigkeit. Sie streben jedoch eine Zusammenarbeit miteinander und mit der gesamten Ungarischen Caritas an. ${ }^{24}$ Die Ungarische Caritas ist gemeinsam mit dem Ungarischen Roten Kreuz, dem Malteser Hilfsdienst in Ungarn und dem ökumenischen Hilfsdienst in Ungarn Mitglied des Karitativen Rates (KT). Derzeit kann man nur noch darauf hoffen, dass der Staat bei der Gestaltung von Sozialgesetzen die Meinung der Mitgliedsorganisationen des KT erfragen wird.

\section{Die Folgen der Zusammenarbeit mit dem postkommunistischen Staat}

Wie bei der Schilderung der Tätigkeiten während des Kommunismus sichtbar wurde, führte die Zusammenarbeit mit dem diktatorischen Staat zu ernsthaften theologischen Abweichungen und teilweise in deren Folge zur Verkümmerung der karitativen Tätigkeit. Aber auch die Arbeit im postkommunistischen Staat ist nicht frei von Problemen und Dilemmas. Zur Untersuchung dieser Dilemmas bzw. der Auswirkungen der kommunistischen Zeit auf die karitative Arbeit sollen hier nach der Erwähnung einiger Rechtsvorschriften die Caritas Hungarica und der Malteser Hilfsdienst in Ungarn verglichen bzw. eine eigenartige Situation dargestellt werden.

In der Republik Ungarn sind Kirche und Staat getrennt. ${ }^{25}$ Diese Setzung bezieht sich auf die formelle Trennung, da eine inhaltliche Trennung von Kirche und Staat unmöglich ist, weil die Gläubigen der Katholischen Kirche zugleich auch ungarische Staatsbürger sind. Obwohl der ungarische Staat seit 1990 gemäß den geltenden Rechtsparagraphen neben den staatlichen Institutionen auch die kirchlichen Einrichtungen (so auch den Ungarischen Caritasverband) fördert, ${ }^{26}$ weicht die juristische (und dementsprechend die finanzielle) Lage des Ungarischen Caritasverbandes grundsätzlich von der des ungarischen Malteser Hilfsdienstes ab. Caritas Hungarica ist die Hilfsorga-

\footnotetext{
tosulnak, s ez utóbbiak az Országos Karitász alá tartoznak. . Sajnos nehéz minden plébánián helyi Karitász csoportot létesíteni a plébánosok túlterheltsége, illetve aránytalan szerepvállalása miatt. Bár mindenki úgy érzi, hogy képes lenne karitatív tevékenységet végezni, valójában ez nem is olyan könnyü. Ezért meg kellett szervezni a Karitász-munkatársképző tanfolyamokat" (aus dem Interview von Péter Török mit Miklós Frank am 13. September 2000).

${ }^{24}$ Durch die Zusammenarbeit werden verschiedene Mitgliedsorganisationen integriert: der RömischKatholische Hilfsdienst, Caritas Collectio, der Transcar Verein, das Hilfswerk Betania, der Helferverein „Forrás“(„Quelle“) und die Stiftung „Fogd a Kezem“ („Halte meine Hand“).

${ }^{25}$ Verfassung der Republik Ungarn, § 60. Siehe auch: Gesetz 1990/IV über die Gewissens- und Glaubensfreiheit sowie § 15 (1) über die Kirchen, Magyarországi egyházak, felekezetek, vallási közösségek 1995-1996 (1996) und ERDÖ \& SCHANDA (1993).

${ }^{26}$ Vergl. Gesetz 1990/IV. über die Gewissens- und Glaubensfreiheit und über die Kirchen sowie $\S 19$ Über die Tätigkeit der Kirchen im kulturellen, sozialen und Gesundheitsbereich.
} 
nisation der Katholischen Kirche und als solche erhält sie keine direkte finanzielle Förderung, sondern nur einen staatlichen Zuschuss zur Förderung des Glaubenslebens. All dies bedeutet ein schwerwiegendes Hindernis in der Arbeit der Ungarischen Caritas. Es ist allgemein bekannt, dass die Katholische Kirche trotz der verschiedenen staatlichen Unterstützungen arm ist, da sie die rückerstatteten verfallenen Gebäude und Schulen aus eigenen Kräften renovieren und die kirchlichen Angestellten mindestens auf dem Gehaltsniveau der öffentlich Bediensteten bezahlen muss. Die Caritas finanziert ihre Tätigkeit ausschließlich durch Spenden und durch die Teilnahme an Wettbewerben und Ausschreibungen, sie erhält auch keine Unterstützung aus dem Ausland, da es in Ungarn keine Katastrophen gab, die ausländische Hilfsorganisationen zur Öffnung ihres Portemonnaies veranlasst hätte. Es ist eine merkwürdige Tatsache, dass von den vier größten Hilfsorganisationen Ungarns nur die beiden keine zweckgebundene (im Staatsbudget garantierte) Förderung erhalten, die unmittelbar einer Kirche angehören (der Ungarische Caritasverband und Ökumenischer Hilfsdienst in Ungarn).

Der Malteser Hilfsdienst in Ungarn (MMSZ) wurde hingegen im Jahre 1989 als ziviler Verein eingetragen. Obwohl der MMSZ in gewisser Hinsicht unter der Ägide des Ungarischen Caritasverbandes steht, ${ }^{27}$ ist er von ihm doch unabhängig und hat andere Möglichkeiten als die Ungarische Caritas. Wie schon angedeutet, bekommt der MMSZ auch eine gewisse finanzielle Förderung vom Staat: Erstmals bekam er 1990 Geld für die Errichtung eines Obdachlosenheimes und Ordinationsraumes, dann eine größere Summe als Förderung aus dem Staatsbudget. Es zeigten sich nicht nur Vorteile auf dem Weg zur Institutionalisierung, sondern auch Nachteile nach der politischen Wende, manchmal in einem ganz seltsamen Gewand. Die Katholische Kirche, genauer gesagt eine Gruppe der Vertreter des Ungarischen Caritasverbandes, ist unsicher geworden, ob der Akzent auf die Unterhaltung eines modellhaften Netzwerks von Facheinrichtungen gelegt werden soll oder eher auf die Förderung von Tätigkeiten, die aus der Gemeinde herauswachsen. Eine bedauerliche Folge dieses Dilemmas war, dass die Caritas auf die Finanzierung und Trägerschaft einer Institution mit Modellcharakter und landesweitem Ruf, des Familienhilfezentrums HÍD (Brücke) verzichtet hat, so dass diese seit 1998 eine Institution ist, die ausschließlich staatliche Aufgaben mit staatlichen Angestellten erfüllt.

Dieser seltsame Fall hängt mit dem Rat für Karitative Hilfe zusammen, dessen Mitglied die Caritas-Stiftung Ungarn ist, da der Staat aufgrund eines einschlägigen Gesetzes die Mitgliedschaft einer kirchlichen juristischen Person nicht akzeptiert. Unlängst hat die Ungarische Katholische Bischofskonferenz beschlossen, dass die Stiftung aus dem Rat für Karitative Hilfe austreten soll, wenn der Staat seinen diesbezüglichen Standpunkt nicht ändert. Auch dies ist ein Beweis dafür, dass der Status als kirchliche juristische Person im heutigen Ungarn immer noch ernsthafte Nachteile haben kann, da das Kriterium nicht darin besteht, welche Tätigkeiten eine Organisation ausführt, sondern wie sie eingetragen ist.

\footnotetext{
${ }^{27}$ Da der Ungarische Caritasverband die katholischen Initiativen zusammenfassen möchte.
} 
Bei der maßlosen Verwüstung, die die Diktatur im Netzwerk der Institutionen verursacht hat, bedeuten die Tätigkeit und die Ausdauer derjenigen, die auch unter den schwierigen Umständen ausgehalten haben, um die Wurzeln zu bewahren, wichtige Ressourcen und ein moralisches Kapital. Dieses moralische Kapital - ergänzt mit charismatischen Initiativen - machte die Erneuerung der religiösen karitativen Tätigkeiten nach 1990 in Ungarn möglich.

Wie man sehen konnte, halten die Kirchen die Bewahrung des Charismas für sehr wichtig und fürchten sich zugleich vor den schädlichen Folgen der Institutionalisierung. Die Kirchen wissen aber auch, dass sie ohne ein institutionelles Netzwerk weder ein „Verhandlungspartner" für die ungarische Gesellschaft werden, noch ihre Tätigkeit entsprechend ihrer Soziallehre in der Europäischen Union durchsetzen können. Vor diesem spannungsvollen Hintergrund vertreten sie die Ansicht, dass die größte Verantwortung der karitativen Organisationen in den ehemaligen sozialistischen Ländern Osteuropas darin besteht, ein institutionelles Netzwerk zu errichten, in dem die Spiritualität beibehalten und den Hilfsbedürftigen - auch vor Ort, auf der Ebene der Gemeinden - mit Fachwissen und christlicher Nächstenliebe geholfen wird. Das könnte eine Lehre aus dem gemeinsamen Erbe des Kommunismus in Ost- und Mitteleuropa sein, die aus der Perspektive der Mentalhygiene unbedingt beachtenswert ist auch im Westen.

Die oben erwähnten vier großen Organisationen können aufgrund ihrer unterschiedlichen finanziellen Möglichkeiten ${ }^{28}$ auch im unterschiedlichen Maß an der Erfüllung karitativer Aufgaben teilnehmen. Zu erwähnen sind auch die Unterschiede in Ausmaß und Anteil der Förderung: Während einige Organisationen über Einnahmen von mehreren Milliarden (Forint) verfügen, kann die Zentrale des Ungarischen Caritasverbandes - Caritas Hungarica auf Jahresebene mit einer Finanzdeckung von etwa 220 Millionen Forint ${ }^{29}$ wirtschaften. Während bei einigen Hilfsorganisationen manchmal über 50\% der Einnahmen vom Staat stammen, macht dieser Anteil bei der Caritas nur ein Drittel ihrer Finanzquellen aus. Mehrere Gründe könnten hierbei im Hintergrund stehen. Die wichtigste Ursache ist vielleicht, dass andere Hilfsorganisationen solche öffentliche Aufgaben oder Teilaufgaben erfüllen, die als staatliche Aufgaben gelten, und sie dafür auch staatliche Förderung erhalten. Die Zentrale von Caritas Hungarica nimmt wegen des niedrigeren Anteils der staatlichen Förderung - mit mehr oder weniger Erfolg - an vielen Ausschreibungen von Fördergeldern teil. Auch die Ungarische Bischofskonferenz unterstützt die Organisation, vor allem durch einen Betriebskostenbeitrag von zehn bis fünfzehn Millionen Forint. Darüber hinaus werden ihre Einnahmen durch andere Zuschüsse der Kirche bzw. von Stiftungen sowie durch Spenden ergänzt.

Hier sollte noch eine Tatsache kurz erwähnt werden: Obwohl der Ungarische Caritasverband von seinen Errichtern bei seiner Gründung ähnlich wie der deutsche

\footnotetext{
${ }^{28}$ Quelle: Die Daten stammen aus den Jahren 2007 und 2008 und sind auf der Web-Seite der jeweiligen Organisationen nachzulesen: http://www.maltai.hu/data/nodes/15/file/merleg.pdf, http://www.voros kereszt.hu/images/stories/pdf/kozhasznusagujelentesek/koltsegvetesi_tablazatok_2008.pdf.

${ }^{29}$ Bericht über die Tätigkeit des Ungarischen Caritasverbandes 2007.
} 
Caritasverband konzipiert wurde, konnte das Konzept wegen der Unterschiedlichkeit des deutschen und des ungarischen Steuersystems nicht umgesetzt werden. Während die Mitglieder der Kirchen in Deutschland auf Grundlage ihres Gehaltes auch Kirchenlohnsteuer an die Diözesen bezahlen, ist dies in Ungarn nicht in das Steuersystem integriert.

Die Zentrale des Ungarischen Caritasverbandes - Caritas Hungarica ist Trägerin des Suchtkranken-Hilfsdienstes „Rév“ (Fährenhafen) ${ }^{30}$, der sich zum Ziel gesetzt hat, Suchtkranken und deren Familien nicht durch ein übliches medizinisches Konzept, sondern durch eine fachlich anspruchsvolle, christlich fundierte, mentalhygienische Denkweise zu helfen (fast 45 Millionen Forint). ${ }^{31}$ Unerlässlich ist auch die Unterstützung anderer hilfebedürftiger Gesellschaftsgruppen, wie zum Beispiel die der Kranken und der Behinderten. Diese Aufgabe wird in der Region Veröce-Szokolya-Zebegény vom Fachpflege- und Behindertenhilfsdienst erfüllt, der ebenfalls die Förderung von Caritas Hungarica genießt (knapp 31 Millionen Forint). Darüber hinaus werden von der Zentrale des Ungarischen Caritasverbandes auch Hilfsaktionen im Inland bekannt gegeben und unterstützt, sie nimmt an humanitären Hilfsaktionen der Caritas International teil (8,5 Millionen Forint) und organisiert auch andere länger oder kürzer dauernde Aktionen im Ausland.

Die Zentrale des Ungarischen Caritasverbandes hat keinen vollständigen Überblick über die Tätigkeiten der Gemeinde- und Diözesan-Caritas-Stellen. Der Unterhalt dieser Organisationen wird von den örtlichen Diözesen übernommen. Von den Spenden, die am Elisabethtag gesammelt werden und fünfzig bis sechzig Millionen Forint betragen, erhalten zwar auch der Römisch-Katholische Hilfsdienst und die Zentrale des Ungarischen Caritasverbandes einen Anteil, aber der größte Teil bleibt am Ort oder wird von der Diözese gesammelt und je nach Bedürftigkeit unter den Caritasgruppen der ärmeren Kirchengemeinden verteilt. Bezüglich der einzelnen DiözesanCaritas-Stellen stehen wenige Daten zur Verfügung, da diese Einheiten ja eine große Selbstständigkeit genießen.

Auch wenn das in der Bilanz und der Gewinn- und Verlustrechnung der Zentrale des Ungarischen Caritasverbandes - Caritas Hungarica und der Gemeinde-CaritasStellen nicht angegeben ist, ist auch die Arbeit der Freiwilligen von großer Bedeutung. Über ihre Beteiligung gibt es keine genauen Daten, aber die Zahl derer, die regelmäßig oder gelegentlich an der Arbeit der Gruppen teilnehmen, wird auf zwanzig- bis fünfundzwanzigtausend geschätzt.

\footnotetext{
${ }^{30}$ Der Suchtkranken-Hilfsdienst „Rév“ („Fährenhafen“) entwickelte sich innerhalb einiger Jahre zu einem Landesnetz mit Standorten in Budapest, Debrecen, Eger, Győr, Kecskemét, Székesfehérvár, Szekszárd und Szombathely. Das Berufsbild des Dienstes kann auf das der psychosozialen Berater zurückgeführt werden, die in Deutschland schon seit 25-30 Jahren erfolgreich arbeiten.

${ }^{31}$ Die weiteren Zahlen sind im „Tätigkeitsbericht des Ungarischen Caritasverbandes 2007“ enthalten.
} 


\section{Syntheseversuche}

Die Übersicht über die karitative Tätigkeit der traditionellen christlichen Kirchen lenkt die Aufmerksamkeit auf zwei teilweise miteinander verbundene Probleme. Das eine ist die Wichtigkeit der Bewahrung von Spiritualität, des reinen Glaubens, die auch bei der Frage der Institutionalisierung auftaucht: Kann die Spiritualität in den großen, zentralisierten Einrichtungen rein bewahrt und angemessen erlebt werden? Das andere Problem weist aber auf die Folgen der Zusammenarbeit mit dem postkommunistischen Staat hin.

\subsection{Bewahrung von Glaube und Spiritualität}

Aus der Geschichte der karitativen Tätigkeit der Reformierten Kirche in Ungarn (RKU) und der Evangelischen Kirche in Ungarn ist sichtbar geworden, dass die Reinheit des Glaubens (Orthodoxie) nicht nur durch auf ideologischen Druck hin entstandene theologische Manipulationen gefährdet wird, sondern in deren Folge auch durch die Trennung von den örtlichen Gemeinden sowie durch die Verkümmerung der Aktivitäten auf Gemeindeebene. Die Bedeutung karitativer Tätigkeiten von und in Pfarreien wird auch von den Katholiken anerkannt, wie das auch in der Feststellung des katholischen Pfarrers Miklós Frank sichtbar wurde.

Auf die Wichtigkeit der Existenz und Tätigkeit der örtlichen Gemeinschaften Pfarreien, Gemeinden - hat auch der Generalsekretär des Ungarischen Caritasverbandes (UCV) - Caritas Hungarica aufmerksam gemacht, dabei aber zugleich auch auf etwas anderes hingewiesen. Bei der Darstellung der drei Schwerpunkte beim Aufbau des Ungarischen Caritasverbandes war es ihm wichtig, Folgendes hervorzuheben:

Es zeichnen sich drei Schwerpunkte ab: (1) Ausbau des Caritasnetzes der Pfarreien, die Stärkung der örtlichen christlichen Gemeinschaften und der Einsatz für Hilfsbedürftige,

(2) Ausbau eines institutionellen Netzwerkes im Sozial- und Gesundheitsbereich und

(3) Koordinierung der karitativen und sozialen Tätigkeit - Netzwerkausbau. Die meiste Angst hat man [im Ungarischen Caritasverband] vor einem institutionellen Netzwerk, obwohl ohne dieses die Kirche auf diesem Gebiet kein Dialogpartner in der Gesellschaft sein wird, d.h. kaum Möglichkeiten zur Durchsetzung der christlichen Soziallehre und später zur positiven Beeinflussung der EU-Sozialpolitik haben wird. Die größte Verantwortung der in den ehemaligen sozialistischen Oststaaten entstandenen Caritasorganisationen besteht darin, dass sie in die Lage versetzt werden, ein institutionelles Netzwerk ins Leben zu rufen, in dem die Spiritualität bewahrt und den Hilfsbedürftigen mit Fachkenntniss und christlicher Nächstenliebe geholfen werden kann ${ }^{32}$ (aus dem Brief des Generalsekretärs des Ungarischen Caritasverbandes - Caritas Hungarica).

\footnotetext{
${ }^{32}$ Eigene Übersetzung. Originaltext: „Három fő csapás körvonalazódik: (1) plébániai karitászhálózat kiépítése, a helyi keresztény közösségek erösítése és a rászorulók felkarolása, (2) szociális és egészségügyi intézményhálózat kiépítése, és (3) karitatív és szociális tevékenység koordinálása - hálózatépítés. Ezek közül [a Magyar Katolikus Karitászban] az intézményhálózattól félnek a legjobban, pedig enélkül
} 
Mit einem wissenschaftlichen Fachbegriff ausgedrückt bedeutet das Achten auf die Spiritualität eine Anstrengung zur Bewahrung des Charismas. ${ }^{33}$ Die karitative Tätigkeit ist ein integrierter Teil der Mission der Kirche. Da diese Mission in menschlichen Gesellschaften und unter deren „Gesetzmäßigkeiten“ ausgeübt werden muss, tritt naturgemäß ein Prozess der Institutionalisierung ein, der in der Fachsprache der Soziologie auch so ausgedrückt werden kann: Das Charisma wird zur Routine. Diese Institutionalisierung wurde freilich von der kommunistischen Macht auch erzwungen: Der Römisch-Katholische Hilfsdienst ${ }^{34}$ - kann man sagen - ist nicht durch eine charismatische, eigene Initiative entstanden, sondern man hat sie dem Staat ,zu verdanken““ ${ }^{35}$ Ähnliche Beispiele für den staatlichen Einfluss und für die Zentralisierung findet man auch bei der RKU und der Evangelischen Kirche. Man konnte aber auch sehen, dass - ähnlich wie die Katholiken - auch die Reformierten und Lutheraner spüren: Obwohl die spontan(er)e Tätigkeit der örtlichen Gemeinden und die institutionalisierte karitative Tätigkeit gleichermaßen unverzichtbar sind, gibt es eine Art Spannung zwischen ihnen, eine Bestrebung nach Herstellung eines angemessenen Verhältnisses. Die gemeinsame Notwendigkeit von Gemeinde- und institutioneller Diakonie wurde besonders schön von der Reformierten Zsófia Juhász veranschaulicht Sie vergleicht diese mit den beiden Kammern des Herzens. Für eine schädliche Änderung des gesunden Verhältnisses zwischen beiden lieferte das Diktum des evangelischen Bischofs Zoltán Káldy ein Beispiel, wonach sowohl die individuelle als auch die Gemeindediakonie im Rahmen der institutionellen Diakonie verwirklicht werden sollte. Gut zu beobachten ist sowohl der Anspruch auf Institutionalisierung wie auch die Sorgen wegen der Institutionalisierung bzw. der Wunsch nach Bewahrung des ursprünglichen Schwungs und des Charismas im Falle des Malteser Hilfsdienstes. Diese Organisation ist um Imre Kozma herum entstanden, einen Pfarrer mit charismatischen Gaben, aber die „Mitbegründerin” Csilla Freifrau von Boeselager plädierte schon von Anfang an für eine Institutionalisierung. Zugleich fürchteten sie sich sehr vor der Institutionalisierung, weil sie nicht bei einzelnen Aufgaben stecken bleiben wollten. ${ }^{36}$

szociális téren az egyház nem lesz tárgyalópartner a társadalomban, tehát a keresztény szociális tanítás érvényesítésére és később az EU szociálpolitikájának pozitív befolyásolására alig lesz lehetősége. A keleti, egykori szocialista országokból induló karitászszervezetek legnagyobb felelőssége az, hogy legyenek képesek olyan intézményhálózatot létrehozni, ahol megmarad a lelkiség és hozzáértéssel, keresztény szeretettel segítenek a rászorulókon.“"

${ }^{33}$ Unter Charisma werden hier vor allem die Begeisterung und Selbstlosigkeit der Gründer verstanden, die natürlich auch im soziologischen Begriff mitenthalten sind (vergl. WEBER 1947, 358-59).

${ }^{34}$ Ungarisch: Római Katolikus Szeretetszolgálat.

${ }^{35}$ Über eine ähnliche ,staatliche Gründung“ könnte man auch im Fall des Frauenordens ,Magyarok Nagyasszonya Rend“" sprechen, der in Ungarn in den 1980er Jahren unter Mitwirkung des Leiters des Staatlichen Kirchenamtes (ÁEH) Imre Miklós entstanden ist.

${ }^{36}$ Beim Spielplatzprojekt und bei der häuslichen Betreuung haben sie über eine Dispatcherzentrale die Möglichkeit erörtert, diese als Beispiele, Modelle zu entwickeln und dann den kommunalen Selbstverwaltungen und anderen zivilen Organisationen zu übergeben. 


\section{Referenzen}

ANDRAS, E. \& J. MOREL (1983) Church in Transition: Hungary's Catholic Church from 1945 to 1982: Collected Studies of the Hungarian Institute for Sociology of Religion (Wien: UKI Reports).

CASAROLI, A. (2001) A türelem vértanúsága: A Szentszék és a kommunista államok, Übers. Cs. SZERDAHELYI (Budapest: Szent István Társulat).

ERDÖ, P. \& B. SCHANDA (1993) Egyház és vallás a mai magyar jogban (Budapest: Szent István Társulat).

FARKAS, R. (2000) A karitativ szervezetek szerepe a társadalom perifériájára szorult emberek gondozásában: Gondozási tevékenység megszervezése egy konkrét intézményben (Dissertation, Szeged: Szegedi Tudományegyetem, Egészségügyi Főiskolai Kar).

Gergely, J. (1985) A Katolikus Egyház Magyarországon 1944-1971 (Budapest: Kossuth).

GÖRGŐY, R. (2001) 'Vallásosság és karrier a kommunizmus alatti Magyarországon', Valóság 7, 31-49.

Magyarországi egyházak, felekezetek, vallási közösségek 1995-1996 (1996) (Budapest: Miniszterelnöki Hivatal Egyházi Kapcsolatok Titkársága) 109.

MÉSzÁRos, I. (1995) A diktatúra és az egyház 1975-1990 III. B.: Az egyház 1975-1988: Kimaradt történelmi tananyag a katolikus egyházról felnötteknek és diákoknak (Budapest: Márton Áron).

MiKLÓs, I. (1987) Az állam és az egyházak kapcsolatáról (Budapest).

RING-EIFEL, L. (2004) Weltmacht Vatikan: Päpste machen Politik (München: Pattloch).

TOMKA, M. (1996) 'Vallás és vallásosság' in R. ANDORKA, T. KOLOSI \& GY. VuKOVICS, Hrsg., Társadalmi riport (Budapest: Tárki) 592-616.

TÖRÖK, J. \& L. LEGEZA (1999) Máltaiak: Szerzetesrendek a Kárpát-medencében (Budapest: Mikes) 46-47.

TÖRÖK, P. (2003) Hungarian Church-State Relations (Budapest: Collected Studies of the Hungarian Institute for Sociology of Religion).

WeBER, M. (1947) The Theory of Social and Economic Organization, Übers. A.M. Henderson \& T. PARSONS (New York: Oxford UP). 